\title{
Família e escola pública: contribuições familiares para o êxito escolar
}

Family and public school: family contributions to the academic success

Haller Elinar Stach Schünemann

Enios Carlos Duarte

Sonia Bessa

Maria Carolina Carneiro

Centro Universitário Adventista de São Paulo

\section{Resumo}

As famílias das escolas públicas são normalmente consideradas, pelo corpo docente, como negligentes e desinteressadas pela escolarização dos filhos. O objetivo dessa

62 pesquisa foi identificar o valor atribuído pela família à escolarização, as práticas desenvolvidas para apoiar as crianças e, ainda, o envolvimento social das famílias. Essa investigação foi feita com aplicação de questionários a 310 pais com filhos em escolas públicas e residentes na periferia de São Paulo. Os resultados demonstraram que a maior parte dos pais valoriza a educação escolar dos filhos e procura participar das reuniões escolares. As práticas de apoio à escolarização também obtiveram resultados positivos, embora, em vários itens, os pais apresentem um apoio insuficiente. Ademais, se constatou que a participação social dos pais na vida escolar é maior do que em outros aspectos comunitários. Portanto, pode-se concluir como equivocada a crença do desinteresse da família pela escolarização dos seus filhos.

Palavras-chave: Família popular. Escola pública. Sucesso escolar.

\section{Abstract}

Families of public schools are usually considered among the teachers as negligent and disinterested by the schooling of the children. Objective of this research was to identify the value assigned by the family to school, practices developed to support children and social involvement of families. This investigation was conducted with questionnaires from 310 parents with children in public schools and residents on the outskirts of São Paulo. The results showed that most parents value the school education of their children and seek to participate in school meetings. Practices in support of education also had positive results, although in several items parents have insufficient support. It also found that social participation of parents in school life is greater than in other respects Community. Therefore, one can conclude how mistaken belief of the low interest of the family for schooling of their children.

Keywords: Family poor. Public school. School success. 
Há quase um consenso entre os professores de que as famílias se interessam pouco pela educação escolar dos filhos. Essa crença é ainda mais intensa quando se refere às classes populares vistas como, de modo geral, negligentes com os filhos. Com frequência, também, são feitas afirmações negativas a respeito das relações familiares dos alunos das escolas públicas, normalmente vistas como desestruturadas. Observamos, dentro da nossa prática como professores de cursos de licenciaturas, que a maior parte desses alunos, mesmo sendo egressos da escola pública, tem uma visão negativa das famílias atendidas pelo sistema público de ensino. É como se já houvesse um consenso prévio de que as famílias dos alunos das escolas públicas são problemáticas e desinteressadas. É possível que esse consenso seja um obstáculo para o trabalho do professor, uma vez que ele já pode contar com uma justificativa a priori para o fracasso dos seus alunos, inibindo uma reflexão a respeito do seu próprio trabalho, ou do funcionamento da instituição escolar. Assim, julgamos fundamental trabalhar com os alunos de licenciaturas um meio de desconstruir tais conceitos, e permitir uma reflexão mais fundamentada sobre o mesmo. Dessa forma, essa pesquisa surgiu da necessidade de desconstruir esse conceito entre os alunos de licenciaturas, envolvidos no projeto PIBID da nossa instituição.

Programa Institucional de Bolsas de Iniciação à Docência (PIBID) foi criado pela Coordenação de Aperfeiçoamento de Pessoal de Nivel Superior (CAPES) em 2007 como uma forma de reverter o quadro negativo dos cursos de licenciatura no país. Os aspectos negativos envolvem tanto uma redução do número de ingressantes e concluintes das licenciaturas, como as dificuldades do recém-formado em se ajustar ao trabalho em função do despreparo para a profissão. Deste modo, o objetivo do PIBID é buscar formas de aperfeiçoar a formação das licenciaturas e favorecer a permanência dos concluintes no magistério. Uma das características desse programa é a flexibilidade dada às instituições para moldar os seus projetos, de forma a buscar experiências diversas e enriquecedoras. Assim, estabelecemos em nossa instituição um projeto com etapas bem definidas: compreensão da dinâmica da vida escolar; atendimento aos alunos com dificuldades escolares e atuação como assistentes; aplicação de recursos didáticos ativos, sob a orientação do professor-supervisor. Dentro da primeira parte do projeto, procedemos a um levantamento de dados sociais, econômicos, culturais e de práticas de escolarização entre as famílias das escolas públicas, onde o projeto é desenvolvido. 
Esse levantamento foi feito a partir de um questionário previamente elaborado pela equipe de coordenação do projeto.

A opção por construir um instrumento e efetivar uma coleta de dados sobre as práticas das famílias em relação à escolarização dos filhos foi motivada pela pequena quantidade de pesquisas sobre o tema, conforme constatado também por Oliveira e Marinho-Araújo (2010).

Deste modo, neste artigo, partilhamos os resultados obtidos sobre o perfil das famílias das escolas públicas da periferia do município de São Paulo, participantes do projeto do PIBID, porque consideramos que os resultados podem contribuir para auxiliar os professores a repensar algumas de suas crenças.

\section{Fundamentação teórica}

A contribuição familiar para o desempenho dos alunos na escola básica é algo bastante evidente. Já na década de 1970, os trabalhos de sociologia da educação de Bourdieu e Passeron (1992) avaliaram a contribuição do fator classe social no desempenho escolar. Na realidade, esses

64 trabalhos quase sugerem um determinismo de classe. Além disso, outros estudos contemporâneos (COLEMAN, 2008; JENCKS, 2008, BARBOSA, 2009) também indicaram uma forte influência da classe social da família na escolarização. Como os desempenhos estavam ligados à dimensão de classe, e os resultados acadêmicos das crianças de famílias populares apresentavam um pior rendimento, construiu-se um consenso de que as famílias de classe popular eram desinteressadas pela escolarização dos seus filhos.

A partir da década de 1990, observamos o surgimento de um olhar mais interessado e profundo em relação às classes populares. Lahire (1997) realizou uma importante pesquisa entre as famílias populares francesas, cuja maior parte é constituída de imigrantes, e percebeu, claramente, que eles reconheciam, na escolarização, algo importante para a integração e melhoria da qualidade de vida dos filhos, embora ele destaque que nem todos os recursos utilizados pelas famílias eram eficientes para garantir que a criança se interessasse pelos estudos ou tivesse êxito escolar. Era quase um pensamento unânime entre os pais, a necessidade de investirem na educação dos filhos.

Nessa mesma linha de pensamento, as contribuições de Thin (2006) destacam os investimentos das classes populares na escolarização dos filhos. 
Embora ele enfatize que as lógicas socializadoras das famílias populares possam estar em conflito com algumas questões escolares, isso não pode ser interpretado como desinteresse pelos filhos ou pela escolarização deles.

No caso brasileiro, temos ainda uma ampla revisão sobre o tema conduzida por Glória (2005) que evidencia a existência de um investimento em classes populares na escolarização dos filhos e algumas pesquisas conduzidas por Nogueira (1998, 2010), apontam na mesma direção.

Apesar de dados indicando que há um investimento familiar e que as famílias de classes populares se interessam na escolarização dos filhos, a percepção de que as famílias não são interessadas ainda permanece um tema recorrente entre professores e no ambiente escolar. Assim, organizamos o instrumento de coleta de dados, de forma que os bolsistas do PIBID pudessem avaliar vários aspectos da vida das famílias com filhos na escola pública, para terem elementos de reflexão a respeito das crenças.

Na construção desse instrumento, propusemos o levantamento de dados em diversas dimensões, como: sociais, econômicas, hábitos culturais e recreativos, práticas associativas e ações familiares para a escolarização das crianças. Nas características sociais, identificamos o perfil de trabalho dos pais, a escolaridade, o tamanho da família e o tipo de habitação, incluindo índices da qualidade de vida urbana, como saneamento, energia, entre outros. Na caracterização econômica, utilizamos o Sistema Brasil, que infere a classe a partir da posse de bens. Esse tipo de levantamento demonstra ser mais fácil de identificar a renda do que uma pergunta direta sobre a mesma. Na parte dos hábitos culturais e recreativos, procuramos ver o acesso aos bens culturais, como frequência a museus, cinemas, teatros, entre outros. Nas práticas associativas, foram incluídas a questão religiosa, envolvimento político partidário, associações de bairros, clubes esportivos e participação na associação de pais e mestres. Por fim, na parte das ações familiares, avaliamos as indicações para local de estudo, valorização e supervisão do mesmo. Esse universo expressivo de questões tinha como propósito tanto mapear o perfil da família usuária da escola pública, como poder verificar algumas relações entre a escolaridade e práticas de ações familiares, e, ainda, avaliar o envolvimento das famílias na escola e em outras práticas associativas. 


\section{Metodologia}

A partir da revisão de literatura, construímos um questionário para traçar o perfil das famílias com alunos nas escolas públicas parceiras do projeto. A proposta orientava que cada aluno, participante do projeto, entrevistasse dez famílias nas escolas onde estavam desenvolvendo as atividades do PIBID. O projeto envolvia 60 alunos bolsistas na cidade de São Paulo. Assim, a expectativa era de obter 600 questionários e realizar um perfil das famílias usuárias das três escolas públicas parceiras no projeto. Essas escolas estão todas localizadas na região sudoeste da cidade de São Paulo, em uma área periférica, onde há bolsões de pobreza. As três escolas parceiras estão próximas a favelas e conjuntos habitacionais populares. Essas escolas não apresentam um bom Índice de Desenvolvimento da Educação Básica (ldeb), todas abaixo de cinco. Dentro do diagnóstico das escolas, todas estaduais, podemos caracterizá-las como tendo predominância de professores não-concursados, estrutura física razoável e número elevado de alunos.

Na coleta de dados, alguns alunos tiveram dificuldades em conseguir fazer o contato com as famílias. Isso, em parte, é devido aos alunos, após 66 alguma idade, realizarem o trajeto casa-escola sem supervisão de adultos, reduzindo a oportunidade de um contato mais fácil. Em média, obtivemos, aproximadamente, sete coletas por alunos. Para garantir a qualidade e a fidelidade dos resultados, acabamos por não incluir no processamento de dados, vários questionários, nos quais as informações não haviam sido preenchidas rigorosamente, dentro do padrão orientado. Para essa pesquisa, incluímos os dados de 310 questionários, que tiveram o preenchimento correto. Mesmo assim, os resultados obtidos foram extremamente significativos e relevantes. $\bigcirc$ objetivo dessa coleta foi fornecer dados para nortear futuras intervenções, e estimular a reflexão dos alunos sobre o perfil encontrado e o imaginado. Nesse artigo, optamos por partilhar os resultados obtidos a respeito das famílias de alunos na escola pública e contribuir para repensar alguns falsos consensos que são atribuídos a essas famílias. Consideramos que os resultados, embora restritos à realidade da periferia paulistana, podem contribuir para entender melhor o universo da escola pública brasileira. 


\section{Resultados}

Para facilitar a análise dos resultados, propomos a apresentação em três categorias. $\bigcirc$ primeiro grupo de resultados apresenta o perfil socioeconômico da amostra da pesquisa; o segundo, as ações familiares na escolarização dos filhos; e o terceiro grupo, a comparação do associativismo em geral das famílias e a sua participação no universo escolar.

\section{Perfil da amostra}

No primeiro grupo de resultados, destacamos a escolaridade dos pais, o tipo de trabalho dos progenitores, o rendimento familiar, o tamanho da família e as condições de habitação.

Estabelecer um perfil da escolaridade dos pais é importante, na medida em que permite entender qual foi, em parte, a vivência anterior deles na escola. Identificar o tempo de escolarização ajuda a verificar o quanto os pais têm de familiaridade com esse universo.

\section{Tabela 1}

Escolaridade de pais/padrasto e mãe/madrasta com filhos em escolas públicas

\begin{tabular}{ccccc}
\hline Escolaridade & Pai & $\%$ & Mãe & $\%$ \\
Analfabeto & 16 & 5,69 & 8 & 2,63 \\
Fund. Incompleto & 114 & 40,57 & 102 & 33,55 \\
Fundamental Completo & 39 & 13,88 & 52 & 17,11 \\
Médio Incompleto & 25 & 8,90 & 44 & 14,47 \\
Médio Completo & 66 & 23,49 & 82 & 26,97 \\
Superior Incompleto & 11 & 3,91 & 7 & 2,30 \\
Superior Completo & 10 & 3,56 & 9 & 2,96 \\
\hline Total & 281 & 100,00 & 304 & 100,00 \\
\hline
\end{tabular}

Os resultados apresentados na Tabela 1 demonstram que o perfil educacional das famílias atendidas é bem diversificado com dois perfis bem significativos: fundamental incompleto e médio completo. Cabe lembrar que o 
número de pais/padrasto e mães/madrasta é inferior ao número total de nossa amostra ( $N=310$ ), porque algumas famílias eram monoparentais. Percebemos que há mais famílias sendo chefiadas apenas pelas mães, do que apenas por pais, o que condiz com o perfil esperado. Um dado importante é que o percentual de pessoas com oito anos ou mais de estudo já compõe um pouco mais de $50 \%$ da amostra em ambos os casos, embora, apenas, cerca de $30 \%$ dos pais em todo o período da educação básica, já possuem uma maior escolaridade que os filhos podem obter ao concluírem o ensino médio.

\section{Tabela 2}

Tipos de situação de trabalho pai/padastro e mãe/madastra

\begin{tabular}{ccccc}
\hline Tipo de Situação de Trabalho & Pai & $\%$ & Mãe & $\%$ \\
Empregado c/ carteira assinada & 156 & 55,52 & 102 & 33,55 \\
Empregado s/ carteira assinada & 13 & 4,63 & 24 & 7,89 \\
Autônomo & 57 & 20,28 & 41 & 13,49 \\
Empreendedor & 3 & 1,07 & 0 & 0,00 \\
Funcionário Público & 4 & 1,42 & 13 & 4,28 \\
Desempregado* & 13 & 4,63 & 49 & 16,12 \\
Aposentado & 10 & 3,56 & 4 & 1,32 \\
Não especificou & 25 & 8,90 & 10 & 3,29 \\
Atividade não remunerada* * & 0 & 0,00 & 61 & 20,07 \\
\hline Total & 281 & 100,00 & 304 & 100,00 \\
\hline * Considera-se desempregado quem está buscando emprego \\
* * Consideramos aqui que alguém que realiza o trabalho doméstico e não está procurando \\
emprego, encontra-se nessa categoria
\end{tabular}

Embora esse tipo de descrição não promova uma indicação de rendimentos, que foi avaliado em outra questão, ela nos permite claramente identificar situações que, combinado com a escolaridade, podem indicar a estabilidade financeira. Um empregado com carteira assinada ou um funcionário público, mesmo com remunerações eventualmente baixas, possuem uma inserção dentro de uma seguridade social, que confere uma possibilidade melhor de vida. Já o empregado sem carteira e autônomo tem, normalmente, rendimentos oscilantes, ou apresenta situação de precariedade no trabalho. Embora uma parte expressiva dos profissionais liberais se enquadre como 
autônomos, a quantidade pequena de sujeitos com ensino superior completo reduz o perfil de autônomo a situação de "bicos" ou um trabalho sem fluxo regular. $\bigcirc$ que nos chamou mais atenção foi a não especificação do trabalho feito por $8,9 \%$ dos pais e 3,3\% das mães. Como já descrevemos na metodologia, essas pesquisas foram feitas junto a, apenas, um dos pais (quase sempre as mães) e, portanto, a ausência da declaração não indica falta de conhecimento, mas a necessidade de omitir alguma situação que pudesse causar constrangimento. Esse dado pode ser bem entendido, ao compararmos com o nível econômico, de acordo com o sistema Brasil.

Tabela 3

Perfil econômico das famílias com filhos em escolas públicas ( $N=310$ )

\begin{tabular}{cccc}
\hline Classe & Pontos & Respostas & $\%$ \\
A1 & $30-34$ & 0 & $0 \%$ \\
A2 & $26-29$ & 0 & $0 \%$ \\
B1 & $21-24$ & 12 & $3,88 \%$ \\
B2 & $17-20$ & 56 & $18,07 \%$ \\
C & $11=16$ & 200 & $64,51 \%$ \\
D & $6=10$ & 42 & $13,54 \%$ \\
\hline Total & & 310 & $100 \%$ \\
\hline
\end{tabular}

Os resultados demonstram que a maior parte dos alunos das escolas públicas atendidas é composta por membros da classe C. Dentro desse processo de classificação, encontramos mais famílias da classe B2, do que da classe D. O sistema de classificação utilizado para definir a renda, é um sistema indireto, em que se identifica a renda a partir de eletrodomésticos e alguns outros aspectos da vida familiar (escolaridade do pai e presença de empregado domésticol para inferir indiretamente a renda. Evidentemente, a renda familiar é uma variável que precisa ser relacionada ao número de pessoas que dependem da renda. No caso, dessa pesquisa, avaliamos o número de filhos por família. 
Tabela 4

Número de filhos nas famílias

\begin{tabular}{ccc}
\hline Número de Filhos & Respostas & $\%$ \\
Um & 42 & $13,55 \%$ \\
Dois & 117 & $37,74 \%$ \\
Três & 75 & $24,19 \%$ \\
Quatro & 42 & $13,55 \%$ \\
Cinco ou mais & 26 & $8,38 \%$ \\
Não especificou & 8 & $2,58 \%$ \\
\hline Total & 310 & $100 \%$ \\
\hline
\end{tabular}

Embora possamos ainda encontrar famílias numerosas, constatamos que praticamente o perfil é de dois filhos por família, sendo que cinco ou mais representam uma parcela pequena, embora não insignificante. A fim de podermos entender com mais clareza esse dado, que é relevante no entendimento da dinâmica familiar em relação à escolarização dos filhos, destacamos o 70 valor da mediana e da média da nossa amostra. A mediana dessa amostra é 2, enquanto a média apresenta um valor mais alto: 2,6 filhos. Esses dados mostram um ajuste feito pela maior parte das famílias ao contexto urbano. Esses dados mostram que o perfil da família da escola pública se aproxima bem da média de filhos do país. $\bigcirc$ valor da média é, significativamente, acima da mediana, e pode ser entendido, quando consideramos que o "peso" das famílias mais numerosas é maior. Mesmo assim, nos chama atenção que, na periferia consolidada de São Paulo, a quantidade de filhos da maior parte das famílias, com filhos nas escolas públicas, esteja entre um e dois filhos. Esse tipo de padrão sugere um planejamento familiar ou, pelo menos, um controle da prole, o que corresponde a um maior investimento afetivo e financeiro em cada filho. Segundo Nogueira (1998), um número menor de filhos gera um maior investimento e um cuidado maior. Desse modo, inferimos que isso sugere que a redução de filhos deve gerar mais interesse sobre a escolarização.

A inclusão do padrão de habitação foi feita porque consideramos que ele pode trazer contribuições para entender o estilo de vida familiar. $O$ padrão de habitação está apresentado na Tabela 5. 
Tabela 5

Estilo de habitação das famílias com filhos na escola pública na periferia paulistana

\begin{tabular}{ccc}
\hline Estilo de Habitação & Respostas & $\%$ \\
Casa isolada em rua padrão normal & 124 & $40,0 \%$ \\
Apartamento em edifício isolado & 3 & $0,97 \%$ \\
Apartamento em conjunto residencial privado & 10 & $3,23 \%$ \\
Apartamento em conjunto residencial popular & 35 & $11,3 \%$ \\
Casa em condomínio fechado & 3 & 0,97 \\
Casa em favela & 31 & $10,0 \%$ \\
Casa em terreno compartilhado & 79 & $25,5 \%$ \\
Não responderam & 25 & $8,06 \%$ \\
\hline Total & 310 & $100 \%$ \\
\hline
\end{tabular}

No item acima, de modo geral, podemos afirmar que "casa em terreno compartilhado" e "casa em favela" estão, quase sempre, associados a um perfil carente. "Apartamento em conjunto residencial popular", também, poderia ser incluído, uma vez que uma boa parte desses conjuntos está associada à habitação popular. Nesse sentido, seria significativo que, por volta de $50 \%$, estariam morando nessas categorias, associados a uma condição pior de moradia.

Ao apresentarmos nessa primeira parte dos resultados o perfil de nossa amostra, podemos identificar que ela é diversificada, sendo que, quase metade, em todos os itens analisados, se aproxima de um perfil, normalmente, associado a uma classe média, embora, com um pequeno viés, mais para a classe média-baixa. Poderíamos afirmar que o "perfil" da família dessas escolas seria um casal que trabalha fora, que tem dois filhos, mora em residência isolada e com o ensino fundamental completo. Pensamos que tal fato indicaria a "típica" família com filhos na escola pública da periferia paulistana.

Accão familiares em relação à escolarização dos filhos

Chegamos ao foco central da pesquisa ao procurar quantificar as ações familiares em relação à escolarização dos filhos. Evidentemente, é 
importante lembrarmos que os dados aqui são baseados nas atribuições que os pais fizeram ao seu próprio comportamento. Mesmo assim, vários dos resultados obtidos são relevantes para verificarmos o investimento das famílias populares na escolarização dos filhos.

A reunião de Pais e Mestres é vista, normalmente, pelos professores como o aspecto mais evidente do interesse da família pela escolarização do filho. Embora a escola considere muito importante, como coloca Torres (2001), nem sempre as práticas escolares favorecem que os pais possam participar dessas reuniões. Em nossa pesquisa, verificamos a importância atribuída pelos pais a essa reunião e a participação deles. Os resultados são apresentados, respectivamente, nas Tabelas 6 e 7 .

\section{Tabela 6}

Importância atribuída pelos pais às reuniões de pais e mestres

\begin{tabular}{ccc}
\hline Grau de Importância & Respostas & $\%$ \\
Muito importante & 217 & $70,20 \%$ \\
Importante & 71 & $23,00 \%$ \\
Pouco importante & 7 & $2,25 \%$ \\
Sem nenhuma importância & 2 & $0,65 \%$ \\
Não responderam & 13 & $3,90 \%$ \\
\hline Total & 310 & $100,00 \%$ \\
\hline
\end{tabular}

Tabela 7

Frequência alegada dos pais as reuniões dos pais e mestres

\begin{tabular}{ccc}
\hline Frequência da participação & Respostas & $\%$ \\
Sempre & 222 & $71,60 \%$ \\
Frequentemente & 54 & $17,40 \%$ \\
Raramente & 22 & $7,10 \%$ \\
Nunca & 3 & $1,00 \%$ \\
Não responderam & 9 & $2,90 \%$ \\
\hline Total & 310 & $100,00 \%$ \\
\hline
\end{tabular}


Os resultados indicam que os pais consideram a reunião muito importante e a maioria participa sempre. Esses resultados são muito positivos, mesmo que a participação efetiva possa ser menor do que a atribuída; esse tipo de afirmativa expressa uma clara valorização da escola.

Ao considerarmos o envolvimento dos pais, também, julgamos relevante avaliar o quanto que eles pensavam ser o interesse dos professores. Na Tabela 8, vemos os resultados, nos quais os pais falam a respeito do interesse demonstrado pelos professores, ao entrarem em contato na reunião de pais e mestres.

\section{Tabela 8}

Grau de interesse dos professores no desenvolvimento acadêmico dos seus alunos segundo a percepção dos pais

\begin{tabular}{ccc}
\hline Grau de interesse dos professores & Respostas & $\%$ \\
Muito Interessados & 110 & 35,5 \\
Interessados & 128 & 41,3 \\
Pouco interessados & 27 & 8,7 \\
Apenas cumprindo o dever & 34 & 10,95 \\
Não responderam & 11 & 3,55 \\
\hline Total & 310 & 100 \\
\hline
\end{tabular}

Esses resultados indicam que, na percepção dos pais, a maior parte dos professores está interessada no desenvolvimento acadêmico. Esse resultado é similar à pesquisa de Pinto, Garcia e Ltichevsky (2006) sobre a satisfação dos pais com a escola pública no Brasil. Um dos resultados principais é a percepção dos pais que os professores, em sua maioria, estão interessados no desenvolvimento dos alunos. Salientamos que os resultados do sistema escolar brasileiro não indicam que a escola brasileira esteja assegurando as aprendizagens mínimas necessárias aos alunos. No entanto, os pais avaliam que, de modo geral, os professores se interessam pela aprendizagem dos alunos.

Além de a participação nas reuniões de pais e mestres ser valorizada, parece um consenso, na escola, a importância de que os pais supervisionem os filhos nas tarefas escolares. Uma queixa comum dos professores é que os pais não supervisionam as tarefas dos filhos. Na Tabela 9, apresentamos os resultados da frequência alegado pelos pais na supervisão da tarefa dos filhos. 


\section{Tabela 9}

Frequência da supervisão alegada pelos pais em relação à tarefa dos filhos

\begin{tabular}{ccc}
\hline Frequência de supervisão da tarefa do filho & Respostas & $\%$ \\
Sempre & 174 & $56,10 \%$ \\
Frequentemente & 77 & $24,80 \%$ \\
Raramente & 35 & $11,30 \%$ \\
Nunca & 12 & $3,90 \%$ \\
Não responderam & 12 & $3,90 \%$ \\
\hline Total & 310 & $100,00 \%$
\end{tabular}

Os resultados indicam que, apenas, uma parcela pequena dos pais afirma que a supervisão não ocorre ou é rara. A maior parte dos pais afirma que faz essa supervisão. Consideramos importante avaliar como os pais veem o envio de tarefas para casa. Essa questão foi proposta de forma a ser um "duplo" com o fator anterior da supervisão. Afinal, a supervisão familiar à tarefa de casa deve ser proporcional ao valor atribuído a essa prática. Vemos

74 na tabela 10 esses dados.

\section{Tabela 10}

Grau de valorização da tarefa de casa para a aprendizagem na visão de pais com filhos na escola pública na periferia paulistana

\begin{tabular}{ccc}
\hline & Respostas & $\%$ \\
Muitíssimo importante & 160 & 51,6 \\
Muito importante & 113 & 36,45 \\
Pouco importante & 24 & 7,75 \\
Nada importante & 2 & 0,65 \\
Não responderam & 11 & 3,55 \\
\hline Total & 310 & 100 \\
\hline
\end{tabular}

Esses resultados estão de acordo como os anteriores. Observamos aqui que a maior parte dos pais considera extremamente importante as tarefas 
de casa para a aprendizagem dos filhos. Isso pode explicar a relação com a afirmação que fazem as supervisões. É claro que a contribuição das tarefas escolares feitas em casa para aprendizagem não constitui um tema sem problemas. Como destaca Carvalho (2000, 2004), esse tipo de exigência feita pela escola é uma sobrecarga quase sempre para a mãe, que é responsável por esse processo de supervisão, ao mesmo tempo, que esbarra nas limitações de conhecimento ou de tempo dos progenitores, em especial, o tempo da mãe.

Ao organizarmos a pesquisa, pensamos que, embora os professores tenham a expectativa de que os pais supervisionem as tarefas, essa prática está, em parte, subordinada ao próprio domínio dos pais sobre os conteúdos escolares. Afinal, se a criança alegar não ter entendimento suficiente para fazer a tarefa, como o pai interferirá caso ele não tenha conhecimento do assunto? Por essa razão, solicitamos aos pais que opinassem sobre as condições pessoais de auxiliarem na tarefa dos filhos. As situações previstas foram: "sentir-se sempre seguro", o sentimento de segurança "depender do assunto" e "sentir-se sempre inseguro". Os resultados estão apresentados na Tabela 11.

\section{Tabela 11}

Avaliação dos pais das condições pessoais de orientar as tarefas escolares recebidas pelos filhos

Autoavaliação da condição de orientar

Segurança em orientá-lo

Depende do assunto me sinto inseguro

Sinto Inseguro

Não opinou
Resposta

120

134

40

16

310
$\%$

38,7

43,25

12,9

5,15

\section{Total}

100

Esse resultado indica que mais da metade dos pais não se sente seguro para auxiliar sempre, ou porque em muitos conteúdos não se sintam seguro em qualquer assunto $(43,25 \%)$ ou porque não acreditam ter conhecimento suficiente para auxiliá-lo $(12,9 \%)$. Se consideramos que as formas de ensinar têm 
sido modificadas, é compreensível que os pais não se sintam seguros. Além do mais, como já destacamos em relação à amostra, cerca de um terço dos pais tem menos de oito anos de escolaridade e que pode sugerir uma dificuldade com a instituição escolar.

Se, por um lado, os pais podem ter limitações nos assuntos escolares, algumas ações, como ter um local fixo e manter a TV desligada durante a tarefa, podem ocorrer, independente do conteúdo escolar. Como um local fixo é associado a um aspecto importante para a formação de hábito de estudos, também investigamos se as crianças tinham um lugar fixo para o estudo.

Na Tabela 12, temos os resultados sobre esse aspecto:

Tabela 12

A criança possui lugar fixo em casa para estudar segundo os pais

\begin{tabular}{ccc}
\hline Lugar fixo para estudar & Respostas & $\%$ \\
Sim & 207 & $66,75 \%$ \\
Não & 92 & $29,70 \%$ \\
Não responderam & 11 & $3,55 \%$ \\
\hline Total & 310 & $100,00 \%$ \\
\hline
\end{tabular}

Esse resultado é bastante interessante, porque encontramos cerca de dois terços dos pais afirmando que o filho dispõe de um lugar para estudo. Esse dado sugere que há uma valorização no sentido de indicar um lugar onde o filho deve realizar as tarefas. Solicitamos que os pais que indicavam um lugar fixo para os filhos, dissessem qual o resultado apresentado na Tabela 13 demonstra que o mais utilizado é o quarto. Considerando o padrão de habitação predominante, é compreensível que a menção de um local, apenas, para estudo seja quase ausente. 
Tabela 13

Cômodo da casa que a criança estuda regularmente ( $\mathrm{N}=207)$

\begin{tabular}{ccc}
\hline Cômodo & Respostas & $\%$ \\
Cozinha & 47 & $22,70 \%$ \\
Quarto & 92 & $44,45 \%$ \\
Sala & 55 & $26,60 \%$ \\
Outros & 8 & $3,85 \%$ \\
Não identificaram & 5 & $2,40 \%$ \\
\hline Total & 207 & $100,00 \%$ \\
\hline
\end{tabular}

A partir apenas da citação do local, não é possível detectar se há uma mesa fixa para estudos, mas é possível supor que a cozinha seja utilizada por ter uma mesa que facilite a escrita. Considerando o perfil da maior parte das moradias é difícil pensar que o quarto, quando utilizado, tenha também uma mesa. Não é possível determinar, apenas, pelo tipo de cômodo, qual o melhor para o estudo. Por exemplo, se pensarmos que, quando há uma TV apenas na casa, é frequente que ela esteja na sala, talvez, esse seja um local com possivel conflito entre o estudo e o lazer.

Assim, uma das questões que procuramos avaliar é se a TV é desligada para o estudo. Os resultados, conforme podemos observar na Tabela 14, não são muito positivos. Mesmo considerando que metade sempre desliga a televisão, cerca da outra metade é desafiada a realizar as tarefas escolares em vários momentos com a TV da casa funcionando, que, em vários casos, subentendemos estar no mesmo cômodo onde a criança realiza a tarefa.

Tabela 14

Frequência com que a TV é desligada para as crianças realizam as tarefas

\begin{tabular}{ccc}
\hline Frequência & Respostas & $\%$ \\
Sempre & 156 & 50,30 \\
Frequentemente & 27 & 8,70 \\
Às vezes & 77 & 24,85
\end{tabular}




\begin{tabular}{ccc} 
Nunca & 37 & 11,95 \\
Não responderam & 13 & 4,20 \\
\hline Total & 310 & 100 \\
\hline
\end{tabular}

Ainda, dentro da esfera das práticas familiares em relação aos estudos, procuramos verificar a disponibilidade do computador e do acesso à internet. Podemos afirmar que, hoje, o investimento em computador conectado corresponde a um investimento de uma enciclopédia na casa, que era feito pelas famílias, em décadas passadas. Assim, procuramos verificar qual o número de famílias que tinham computador e quantos desses estavam conectados.

Os resultados demonstraram que $60 \%$ das famílias têm computador em casa. E desses, 85\% estão conectado à internet. Assim, na amostra geral, $50 \%$ das famílias têm acesso à rede. É evidente que a posse de computador e a manutenção do serviço de internet constituem em investimento que nem sempre as famílias mais pobres conseguem fazer. Contudo, consideramos importante destacar que a presença dos computadores e, mesmo da internet, indica um universo da escola pública diferente daquele que é representado de

78 forma preconcebida em vários discursos.

Obviamente, que os livros representam um investimento proporcionalmente menor. Além disso, é possível obter bons livros em bibliotecas. Embora a distribuição de bibliotecas públicas em um município como São Paulo deixe a desejar, mesmo na região de periferia pesquisada há oferta de bibliotecas públicas. Assim, procuramos verificar a oferta de livros a que as crianças têm acesso. Na Tabela 15, apresentamos os resultados.

Tabela 15

Acesso aos livros entre crianças de escola pública segundo os pais

\begin{tabular}{ccc}
\hline Frequência & Respostas & $\%$ \\
Frequentemente & 90 & 29,05 \\
Raramente & 95 & 30,65 \\
Nunca & 107 & 34,50 \\
\hline
\end{tabular}


Não responderam

Total
18

310
5,8

$100 \%$

Esses resultados são menos animadores, do que o acesso à internet. Queremos destacar que a pergunta indagava sobre oferecer livros aos filhos, que não fossem exigência da escola. A pergunta, intencionalmente, não separava a compra de livros, ou a retirada na biblioteca. Consideramos que o importante é o acesso aos livros como fonte de informação e lazer, portanto, ao incluirmos o acesso às bibliotecas públicas na mesma questão, tentamos identificar o quanto a família desenvolve ações que visem oferecer livros às crianças. Dentro desse perfil, vemos que, nesse item, o investimento é pequeno, pois um pouco menos de um terço afirmou fazer essa ação frequentemente.

É importante destacar que as três escolas pesquisadas se encontram em bairros da cidade de São Paulo considerados como de periferia, e, dentro dos estudos de Marques e Torres (2005), podem ser classificados como periferia consolidada. Em outras palavras, locais que, mesmo tendo um perfil maior de população de baixa renda, já possui uma estrutura urbana consolidada e que apresenta, também, amplos segmentos de uma classe média-baixa. Podemos perceber que essas escolas, mesmo estando próximas a favelas e conjuntos habitacionais populares, também possuem um segmento de alunos que vem de famílias de classe média ou média-baixa. Assim, ao analisarmos o que seria a típica família da escola pública, deparamos com um quadro diferente do descrito nas queixas dos professores. Isso não quer dizer que estas sejam falsas, mas nos sugerem que estão supervalorizadas. É como se os segmentos mais vulneráveis da população correspondessem à totalidade da realidade escolar.

Ao identificarmos uma realidade diversificada, somos tentados a fazer inferências sobre o quanto a escolarização dos pais está relacionada com um investimento maior na escolarização. Sabemos que os pais de classe média fazem grandes investimentos na escolarização dos filhos, uma vez que essa ação é percebida como fundamental para ascensão social (NOGUEIRA, 2010). Mais, do que isso, a autora aponta para um aumento da concorrência pela escolarização, que pode ser entendido, como o reconhecimento entre os segmentos mais populares da importância do sucesso escolar. Assim, 
precisamos verificar se a escolaridade dos pais explicaria ainda uma maior ou não valorização da escolarização. A comparação efetuada se deu entre a escolaridade dos pais e as práticas escolares de supervisão das tarefas dos filhos ou na valorização da participação da reunião de pais e mestres. Os resultados para essas variáveis demonstraram uma correlação menor do 0,1 em todos os aspectos combinados. Tal fato significa que a maior escolaridade dos pais não leva a uma melhor atribuição de valor em participar das reuniões de pais e mestres; bem como a maior escolaridade não resultava em uma supervisão mais frequente das tarefas. Esses resultados estão de acordo com o que afirmam Maimoni e Bertoni (200 1) que constatam que a contribuição dos pais não está dimensionada pela escolaridade desses.

Ao mesmo tempo que percebemos que existe um consenso mesmo entre as famílias populares na escolarização dos filhos, afirmamos que nem todas as ações de envolvimento dos pais são positivas. Como adverte Lahire (1997), nem todas as ações educativas dos pais serão efetivamente proveitosas. Entre alguns problemas que a família pode trazer no envolvimento, é, segundo Costa, Cia e Braham (2007), a realização da tarefa pela mãe ao invés de ser feita pela criança. Desejosos de garantir o êxito da criança no 80 processo escolar, as mães acabam, muitas vezes, efetuando a atividade no lugar do filho. A questão é que, muitas vezes, essa ação é aprovada, indiretamente na escola, quando a criança obtém uma boa nota. Outro aspecto do envolvimento dos pais que pode ser negativo é destacado por Scarpelli, Costa e Souza (2006). Os autores apresentam que a tarefa de casa - uma extensão dos processos de aprendizagem no âmbito familiar - é um processo que pode contribuir também para piora do processo de aprendizagem, uma vez que os pais, embora possam estar bem motivados a auxiliar os filhos, nem sempre conseguem perceber que o aumento da punição em situações de dificuldade escolar, não será um fator de contribuição favorável à aquisição da aprendizagem da criança.

Considerando que esses dados foram respondidos, com alto grau de valorização da escola e da supervisão das tarefas, pensamos que esses resultados demonstram uma universalização do valor atribuída à escolarização, o que não deve ser confundido com a inexistência de problemas na escolarização da criança. Mesmo analisando os dados dos segmentos menos escolarizados, não foi possível obter um resultado significativo de diferença na participação nas reuniões de pais e mestres, ou mesmo na afirmação da supervisão das 
tarefas. Esses dados nos sugerem que os processos comumente atribuídos de desinteresse aos pais de filhos nas escolas públicas representam mais uma incompreensão dos agentes educativos, em especial os professores, das limitações das famílias, do que uma avaliação correta, embora possa reconhecer a existência de algumas limitações do instrumento utilizado nessa pesquisa.

Esses dados podem demonstrar algumas tensões envolvidas nas ações familiares. Constatamos que os pais valorizam a escolarização, mas podem não ser suficientemente disciplinados para desligar a TV a fim de dar prioridade à atividade escolar dos filhos ou podem não se mobilizarem, suficientemente, para levar o filho a uma biblioteca pública, para ter acesso a livros e contribuir para melhoria da capacidade de leitura.

\section{Associativismo nas famílias populares}

Por fim, consideramos fundamental destacar o envolvimento dos pais com a vida escolar em relação ao associativismo no Brasil de modo geral. $\bigcirc$ associativismo, dentro dos parâmetros colocados por Avritzer (2004), envolve uma ação voluntária, na qual as pessoas se mobilizam para benefícios coletivos. Ele destaca que, após uma expansão do associativismo no Brasil, após o fim da ditadura militar e no processo de redemocratização, ao longo da década de 1990 e início do século XXI, o processo de associativismo permaneceu estagnado. Dentro da estrutura escolar, a Associação de Pais e Mestres serve como importante meio de envolver os pais na condução da escola e, portanto, está relacionado com a valorização do processo escolar. Paro ( 1995 ) apresenta a importância da Associação de Pais e Mestres (APM) como instrumento de engajamento na condução escolar e considera positivo que as famílias se envolvam nesse processo, visando obter melhorias no sistema público de ensino que, de modo geral no Brasil, está aquém das necessidades sociais. Assim, na pesquisa, consideramos importante avaliar a participação dos pais na APM das escolas. 
Tabela 16

Participação dos pais na APM da escola segundo sua percepção

\begin{tabular}{ccc}
\hline $\begin{array}{c}\text { Participa da Associação de Pais e } \\
\text { Mestre da escola }\end{array}$ & Respostas & $\%$ \\
Sim & 130 & 41,9 \\
Não & 150 & 48,4 \\
A escola não possui & 13 & 4,2 \\
Não responderam & 17 & 5,5 \\
\hline Total & 310 & 100 \\
\hline
\end{tabular}

Podemos ver que, apenas, 41,9\% declaram participar, alguns não souberam responder. Vemos que cerca de 4,2\% alegaram que a escola não possuía, mas todas as escolas a partir da qual as famílias foram contatadas, tinham uma APM. Não podemos saber se não conheciam, porque não é bem divulgado, ou não tinham interesse em participar.

Analisando, isoladamente, esse resultado, no qual a maior parte dos

82 pais não participa, podemos pensar em um quadro negativo e que, em parte, contradiz aquilo que apresentamos anteriormente. Contudo, em nossa pesquisa, incluímos outras formas de associativismo. Na Figura 1, verificamos o envolvimento em outros tipos de associativismo. 
Figura 1

Comparação do associativismo dos pais com filhos em escola pública na periferia de São Paulo

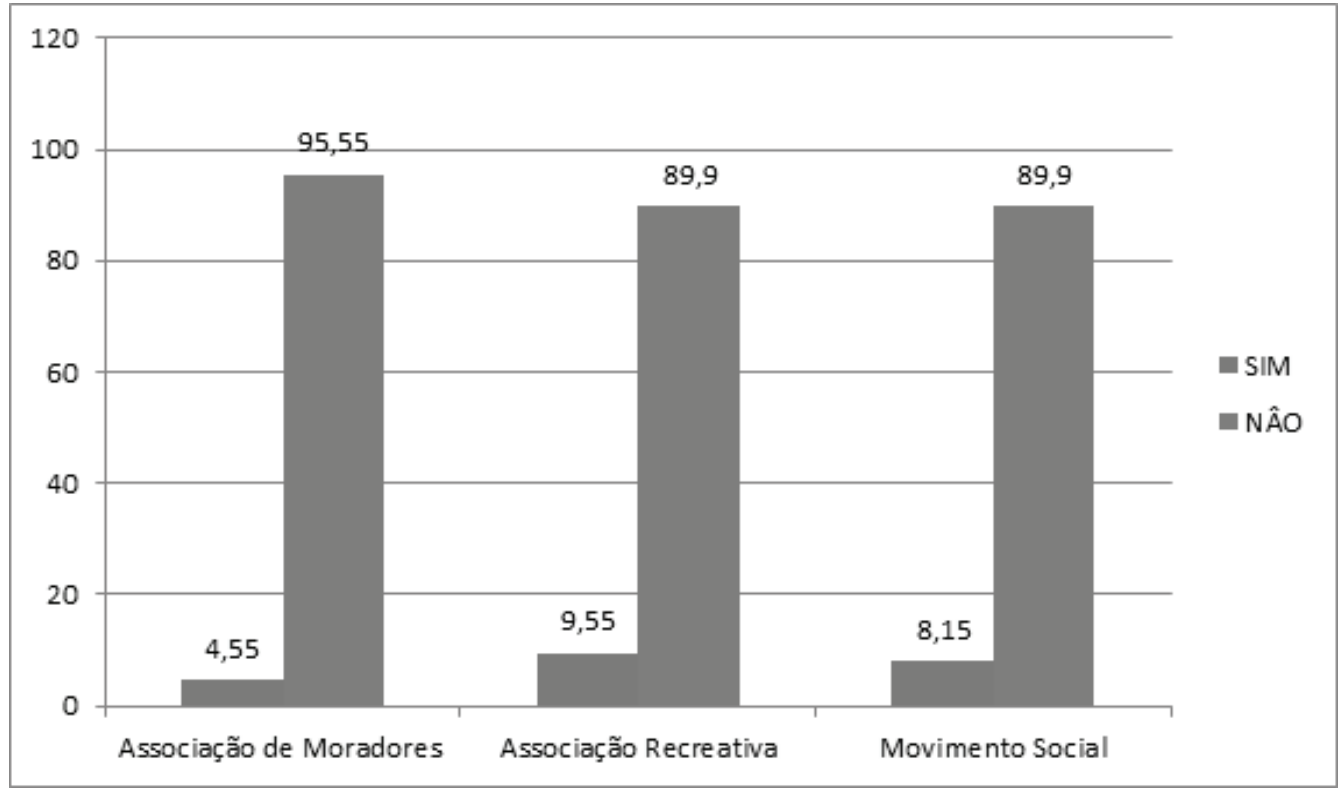

Quando comparamos o associativismo dos pais, evidenciamos que o envolvimento escolar é muito maior. Observem que dos fatores avaliados todos eles estavam abaixo de 10\% de participação. Se considerarmos que cerca de $40 \%$ dos pais entrevistados afirmaram participar da APM, pensamos que isso indica uma valorização expressiva do processo de escolarização. $\bigcirc$ engajamento social no Brasil apresenta resultados gerais não muito favoráveis. A amostra da nossa pesquisa está um pouco abaixo da média nacional, mas, aqui, não destacamos o associativismo religioso, o qual é responsável por, normalmente, elevar o índice do associativismo em geral. ' Esse quadro em que a participação nas reuniões da APM envolve cerca de 40\% demonstra que existe, de fato, um significativo interesse dos pais na escolarização dos filhos. 


\section{Considerações finais}

Ao avaliarmos os resultados gerais, podemos constatar um elevado interesse das famílias de classes populares pela escolarização dos seus filhos. É evidente que isso não significa que todas as famílias valorizem a escolarização, ou mesmo se interessem pelos filhos. Os resultados obtidos demonstram a existência de famílias negligentes, dentro da tipologia trabalhada por Weber, Prado, Viezzer e Brandenburg (2004). Embora não aplicando o teste de estilo parental, verificamos que várias das respostas que demonstravam pouco ou nenhum interesse pelo desempenho escolar dos filhos, foram dados pelos mesmos sujeitos. Itens como - não supervisionar as tarefas, considerar essas sem valor, não indicar a frequência da participação das reuniões de pais e mestres, não desligar nunca a TV para favorecer a execução das tarefas dos filhos apresentaram um grau elevado de correlação entre si. Não temos dúvidas de que existem alunos na escola pública que são filhos de pais negligentes. No entanto, esses resultados apontam esse tipo de família com a minoria. Talvez, porque esses alunos, oriundos de famílias negligentes, causem transtornos aos professores, parece que eles são mais numerosos do que, de fato, são. Ao

84 estabelecermos um perfil das famílias, podemos perceber a valorização da escolarização, embora algumas ações complementares estejam aquém da necessidade para ampliar o sucesso escolar dos filhos. Pensamos que resultados sobre a oferta de livros ou desligar a TV para execução das tarefas escolares, estão aquém do que seria esperado pela valorização. Ou seja, há um segmento significativo que valoriza a escolarização, mas parece ainda não ter desenvolvido ações que permitam melhor alcançar esse objetivo. É bem provável que sejam resultados até de uma compreensão reduzida da importância dessas ações, ou mesmo a limitação pessoal em operacionalizá-las.

Assim, acreditamos que tais resultados demonstram um envolvimento significativo e relevante das famílias na escolarização dos filhos, mesmo que eles estudem em escolas públicas. Os problemas encontrados pelos professores no processo de ensino não estão relacionados à falta de valorização familiar, mas sim, a outras limitações existentes. 


\section{Nota}

1 A razão de excluirmos esse item em nosso estudo foi que o associativismo religioso não é o mesmo que filiação a uma igreja.

\section{Referências}

AVRITZER, Leonardo; RECAMÁN, Marisol; VENTURI, Gustavo. O associativismo na cidade de São Paulo. In: AVRITZER, Leonardo. A participação em São Paulo. São Paulo: UNESP, 2004.

BARBOSA, Maria Ligia de Oliveira. Desigualdade e desempenho: uma introdução à sociologia da escola brasileira. Belo Horizonte: Argumentum, 2009.

BOURDIEU, Pierre; PASSERON, Jean-Claude. A reprodução: elementos para uma teoria do sistema de ensino. 3. ed. Rio de Janeiro: Francisco Alves, 1992.

CARVAlHO, Maria Eulina Pessoa. Relações entre família e escola e suas implicações de gênero. Cadernos de Pesquisa, São Paulo, n. 1 10, p. 143-155, jul. 2000.

CARVAlHO, Maria Eulina Pessoa de. Escola como extensão da família ou família como extensão da escola? $\bigcirc$ dever de casa e as relações família-escola. Revista Brasileira de Educação, Rio de Janeiro, n. 25, p. 94-104, 2004.

COLEMAN, James Smoot. Desempenho nas escolas públicas In: BROOKE, Nigel; SOARES, José Francisco (Org.) Pesquisa em eficácia escolar: origem e trajetória. Belo Horizonte: Editora UFMG, 2008.

COSTA, Carolina Severino Lopes da; CIA, Fabiana; BARHAM, Elizabeth Joan. Envolvimento materno e desempenho acadêmico: comparando crianças residindo com a mãe e com ambos os pais. Psicologia Escolar e Educacional, Maringá, v. 1 1, n. 2, p. 339-351, jul./ dez. 2007.

GLÓRIA, Dilia Maria Andrade. Relação entre Escolaridade e Diferenças Constitutivas das Fratrias. Paídeía, Ribeirão Preto v. 15, n. 30, p. 31 -42, jan./abr. 2005.

JENCKS, Christopher. Desigualdade no aproveitamento educacional In: BROOKE, Nigel; SOARES, José Francisco (Org.). Pesquisa em eficácia escolar: origem e trajetória. Belo Horizonte: Editora UFMG, 2008.

LAHIRE, Bernard. Sucesso escolar nos meios populares. São Paulo: Editora Ática, 1997. 
MAIMONIL, Eulália H.; BORTONE, Márcia E. Colaboração família-escola em um procedimento de leitura para alunos de séries iniciais. Psicologia Escolar e Educacional, Maringá, v. 5, n. 1, p. 37-48, jan./jun. 2001.

MARQUES, Eduardo; TORRES, Haroldo (Org.). São Paulo: segregação, pobreza e desigualdades sociais. São Paulo: SENAC-SP, 2005.

NOGUEIRA, Maria Alice. Classes médias e escola: novas perspectivas de análise. Currículo Sem Fronteiras. v. 10, n. 1, p. 213-231, jan./jul. 2010.

NOGUEIRA, Maria Alice. Relação família-escola: novo objeto na sociologia da educação. Paídeia, Ribeirão Preto, v .8, n.14, p. 91-103, fev./ago. 1998.

OlIVEIRA, Cynthia Bisinoto Evangelista de; MARINHO-ARAUJO, Claisy Maria. A relação família-escola: intersecções e desafios. Estudos em Psicologia, Campinas, v. 27, n. 1, p. 99-108. mar. 2010.

PARO, Vitor Henrique. Por dentro da escola pública. São Paulo: Editora Xamã, 1995.

PINTO, Fátima Cunha Ferreira; GARCIA; Vanessa Coelho; LETICHEVSKY, Ana Carolina. Pesquisa Nacional Qualidade na Educação: a escola pública na opinião dos pais. Ensaio:

SCARPELLI, Paula Brandão; COSTA, Carlos Eduardo; SOUZA, Sílvia Regina de. Treino de mães na interação com os filhos durante a realização da tarefa escolar. Estudos de Psicologia, Campinas, v. 23, n. 1, p.55-65, mar. 2006.

THIN, Daniel. Para uma análise das relações entre famílias populares e escola: confrontação entre lógicas socializadoras. Revista Brasileira de Educação, Rio de Janeiro, v. 11 , n. 32, p. 21 1-225, maio/ago. 2006.

TORRES, Rosa Maria. Itinerários pela educação latino americana: caderno de viagem. Porto Alegre: Artmed, 2001.

WEBER, Lidia Natalia Dobrianskyj; PRADO, Paulo Müller; VIEZZER, Ana Paula e BRANDENBURG, Olivia Justen. Identificação de estilos parentais: o ponto de vista dos pais e dos filhos. Psicologia: Reflexão e Crítica, Porto Alegre, v. 17, n. 3, p. 323-331, 2004. 
Prof. Dr. Haller Elinar Stach Schünemann Centro Universitário Adventista de São Paulo Curso de Pedagogia Líder Grupo de Estudo de Formação Docente Coordenação Institucional PIBID/UNASP E-mail | haller_schunemann@yahoo.com.br

Prof. Ms. Enios Carlos Duarte Centro Universitário Adventista de São Paulo Curso de Biologia Membro Grupo de Estudo de Formação Docente Coordenação Biologia PIBID/UNASP E-mail | enios.duarte@unasp.edu.br

Profa. Dra. Sonia Bessa Centro Universitário Adventista de São Paulo Curso de Pedagogia Membro Grupo de Estudo de Formação Docente Coordenação Pedagogia PIBID/UNASP E-mail | sonia.bessa@unasp.edu.br

Profa. Dra. Maria Carolina Cascino da Cunha Carneiro Centro Universitário Adventista de São Paulo Curso de Matemática Membro Grupo de Estudo de Formação Docente Coordenação Matemática PIBID/UNASP E-mail | mcarolccc@uol.com.br 